\title{
Parceria público-privada: compreendendo o modelo brasileiro'
}

Barbara Moreira Barbosa de Brito e Antonio Henrique Pinheiro Silveira

\section{Introdução}

Os anos 80 marcaram o início de profundas modificações na ação econômica estatal pelos governos dos países membros da Organização para a Cooperação e o Desenvolvimento Econômico (OCDE). Tendo na vanguarda as administrações Reagan e Thatcher, respectivamente nos EUA e no Reino Unido, esse processo traduziu-se numa ampla tendência de desregulamentação setorial, particularmente no âmbito financeiro, acompanhada de reversão da progressividade da ordem tributária e indução seletiva à competição internacional. Com variada intensidade, esses movimentos estenderam-se a praticamente todos os países do globo, refletindo-se no padrão das relações entre os setores público e privado.

Um dos reflexos mais nítidos desta tendência foi a reorganização patrimonial do setor público, por meio dos grandes processos de desestatização, que interferiu de maneira decisiva na forma de provimento de bens e serviços públicos. Em 
boa parte do mundo, isso se traduziu na transferência, por venda ou concessão, de empresas estatais à iniciativa privada; mas, mesmo aqueles países que mantiveram parte de seus sistemas produtivos na esfera estatal como alternativa estratégica, acabaram por introduzir importantes mudanças nos respectivos sistemas de gestão².

Em relação às políticas fiscais nacionais, diferentes fatores provocaram movimentos convergentes. Entre os países emergentes da Ásia e da América Latina, as crises cambiais da segunda metade dos anos 90 acabaram por forçar regimes fiscais contracionistas, em maior ou menor grau. $\mathrm{Na}$ realidade européia, a crescente importância estratégica do bloco regional de comércio e investimento, como resposta ao recrudescimento da concorrência internacional, impôs aos países severos critérios de ajustamento e coordenação macroeconômica ${ }^{3}$.

A provisão de serviços de infra-estrutura foi diretamente afetada por essas tendências. Traduzida geralmente em projetos de grande porte e de longo período de maturação, de um lado, e com importância estratégica pelas externalidades e ganhos de eficiência associados, de outro, as reestruturações patrimoniais e as restrições fiscais impactaram fortemente nas formas de financiamento das ações nesse campo. $\mathrm{Na}$ medida em que algumas experiências objetivas mostraram que o modelo puro de privatização era problemático em setores de utilidade pública com forte predominância de monopólios naturais, inovações no âmbito da estruturação dos empreendimentos foram introduzidas, ao lado de aprimoramentos no a parato regulatório. Incapacitados de dar continuidade a uma tradição histórica de financiamento fiscal dos grandes investimentos públicos, governos de diversos países identificaram, na parceria com o setor privado, uma alternativa para viabilizar projetos de infra-estrutura e de provisão de serviços públicos.
Foi no Reino Unido que tal movimento se deu com maior intensidade. Em 1992, ainda sob a administração do conservador John Major, foi lançado o embrião do programa de parcerias inglês, a Private Finance Iniciative (PFI). Como a própria terminologia denota, o objetivo principal era viabilizar projetos por meio do financiamento privado, uma vez que a capacidade de implementá-los da forma tradicional, se não estava esgotada, estava ao menos reduzida pelos limites impostos pelo Tratado de Maastricht ${ }^{4}$.

Mas foi somente em 1997, já no governo do trabalhista Tony Blair, que o programa foi aprofundado. Ampliado e rebatizado de Public-Private Partnerships $(\mathrm{PPP})^{5}$, o programa tinha por objetivo mudar a forma de contratação de obras e serviços públicos, saindo da maneira tradicional de aquisição de ativos para uma lógica de compra de serviços. A busca por alternativas de financiamento permanecia no centro da questão, mas o objetivo maior passou a ser a eficiência na contratação de serviços públicos.

Além do Reino Unido, diversos países vêm desenvolvendo programas de parcerias. Com diferentes graus de intensidade e sucesso, projetos de PPP estão em andamento em Portugal, Espanha, Finlândia, Grécia, Itália, Irlanda, Holanda, Canadá, Austrália, África do Sul, entre outros. $\mathrm{Na}$ América Latina, Chile e México foram os pioneiros no uso da PPP para a provisão de infra-estruturas e serviços públicos.

O modelo brasileiro emprega a terminologia PPP em seu sentido estrito: é uma forma de provisão de infra-estruturas e sewiços públicos em que o parceiro privado é responsávelpela elaboração do projeto, financiamento, construção e operação de ativos, que posteriormente são transferidos ao estado. O setorpúblico torna-se parceiro na medida em que ele é comprador, no todo ou emparte, do serviço disponibilizado. O controle do contrato passa a ser por meio de indicadores relacionados ao 
desempenho na prestação do serviço, e não mais ao controle físico-financeiro de obra.

Nesse contexto, as parcerias não devem ser confundidas com as privatizações. Embora resultantes de um mesmo processo de reforma e modernização do Estado, as privatizações implicam a alienação de ativos públicos ao setor privado, enquanto nas PPP ocorre o inverso: ao término do contrato, a infra-estrutura implementada é transferida ao setor público.

Ainda que a lei brasileira enquadre as PPP como uma forma de concessão, elas se diferenciam das tradicionais no que se refere às fontes de remuneração do parceiro privado. Nas concessões tradicionais, a cobrança de tarifas é suficiente para remunerar o investimento. Já nas PPP, abre-se espaço para uma complementação de receitas por parte do setor público, de modo a tornar o empreendimento viável. Nos casos em que não há cobrança de tarifa do beneficiário - ou quando a administração é a usuária, direta ou indireta, cabe ao poder público efetuar o pagamento integral pelo provimento do serviço.

Mesmo apresentando possibilidades de aplicação bastante amplas, tendo sido utilizada em setores como transportes, educação, saúde, habitação e até mesmo em projetos de tecnologia da informação, a contratação por meio de PPP não substitui a obra pública tradicional. Há determinados empreendimentos que resultariam em um elevado prêmio por transferência de riscos ao setor privado, não sendo, portanto, adequados a PPP. Além disso, questões estratégicas e políticas em setores como defesa e segurança pública, e mesmo nas áreas de educação e saúde, demandam cautela no uso das parcerias.

A discussão sobre a adoção de um programa de parcerias no Brasil começou em 2002, mas foi somente em dezembro de 2004 que a Lei de PPP - Lei no 11.079/ 2004 - foi aprovada. Tendo em vista o debate público que se seguirá por ocasião da aplicação da lei e da definição dos projetos prioritários, esse artigo tem por objetivo expor as principais questões relativas ao tema. Apresenta-se, na segunda parte, uma discussão teórica acerca da justificativa de se adotar um programa de parcerias. Em seguida, é feita uma descrição das características de uma PPP, com destaque para a estrutura contratual e riscos mais usuais. Na quarta parte, é delineado o

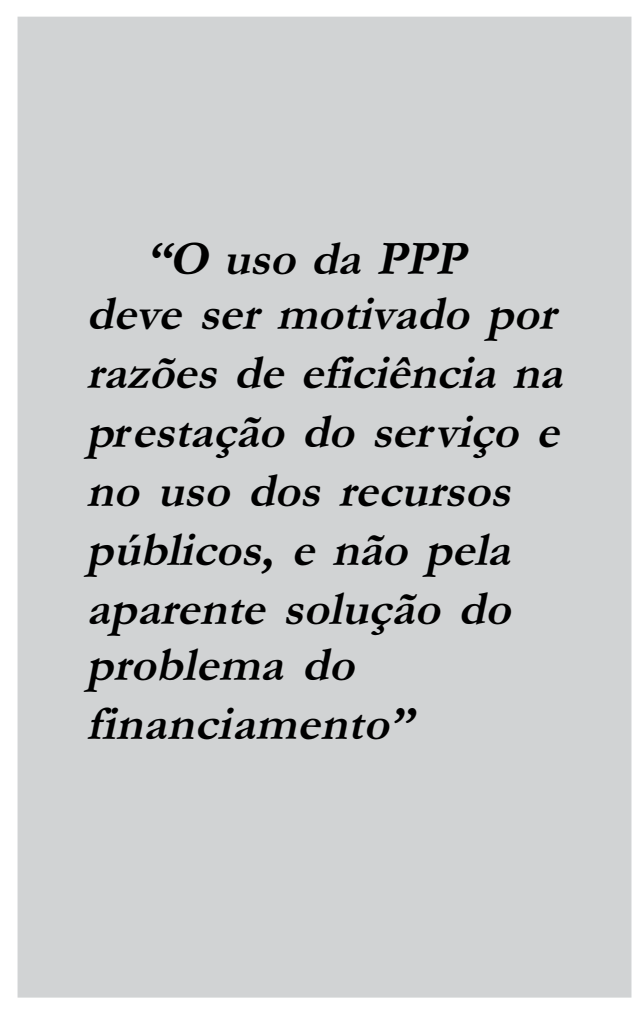

programa de PPP brasileiro, com base na legislação que disciplina a contratação de parcerias pela administração pública. Segue, por fim, a conclusão do artigo.

\section{Fundamento econômico}

Duas questões permeiam o debate econômico em torno da justificativa de se adotar um programa de parcerias público-privadas: a obtenção de espaço 
orçamentário para viabilizar investimentos em um quadro de restrição fiscal e a eficiência na prestação de serviços públicos.

A partir dos anos 80, os governos de diversos países passaram a enfrentar, em maior ou menor grau, restrição na sua capacidade de investimento. Seja por conseqüência do aumento dos gastos sociais e de previdência, seja por uma necessidade premente de estabelecer uma disciplina fiscal para atender a limites de déficit e de dívida, o fato é que se iniciou um processo de contenção do gasto, que resultou em limitação da capacidade de financiamento público do investimento.

Nesse contexto, a PPP foi vista como alternativa para viabilizar investimentos, particularmente em infra-estrutura, sem que isso causasse impactos imediatos sobre o quadro de endividamento público. Muitos países adotaram programas de PPP atraídos pela possibilidade de se diluir no tempo o montante de recursos necessários para viabilizar investimentos, permitindo a realização simultânea de um maior número de projetos. Em alguns casos, a conta não demorou a chegar. Portugal, por exemplo, enfrenta atualmente sérios problemas para honrar os compromissos de PPP resultantes dos contratos de rodovias em pedágio-sombra ${ }^{6}$.

A crença de que a PPP representa a superação definitiva da restrição fiscal ao financiamento de investimentos públicos é, portanto, errônea. Quando mal concebida e, sobretudo, quando mal administrada, a PPP pode vir a acentuar crises fiscais. É verdade que uma das vantagens de se instituir uma parceria que inclua o aporte de capital privado é a possibilidade de antecipar um benefício econômico e social que só seria possível no longo prazo (MERNA; SMITH, 1994). Isso, no entanto, está invariavelmente associado a um comprometimento de receitas futuras.

É por essa razão que o uso da PPP deve ser motivado por razões de eficiência na prestação do serviço e no uso dos recursos públicos, e não pela aparente solução do problema do financiamento. Há um extenso arcabouço teórico que orienta a discussão acerca das razões pelas quais a prestação de serviços públicos por meio de contratos de parceria com o setor privado pode ser, em alguns casos, mais eficiente que a contratação tradicional de obra e serviços públicos.

Uma linha de argumentação defende a idéia de que empresas privadas são mais eficientes que entidades estatais no que tange à inovação e à gestão de recursos. Isso seria atribuído à estrutura de incentivos, limitação de pessoal e à própria restrição orçamentária a que estaria sujeita a administração pública ${ }^{7}$. São argumentos que, no entanto, concentram-se na eficiência produtiva, desconsiderando o fato de que, quando se trata da prestação de serviços públicos, a presença de importantes externalidades positivas e a recorrência de situações de monopólio natural tornam mais importante o conceito da alocação socialmente eficiente ${ }^{8}$.

Nos contratos de PPP, a eficiência advém da possibilidade de integrar elaboração de projeto, construção e operação de infra-estruturas em um único agente, $\mathrm{o}$ que gera incentivos não só para a otimização de custos em uma lógica de ciclo de vida do projeto, mas, sobretudo, para uma melhor qualidade na prestação do serviço, sem prejuízo da dimensão estratégica do planejamento da política pública. Desta forma, o governo deleg a ao setor privado aspectos tipicamente mercantis do empreendimento, mantendo suas prerrogativas de planejamento, monitoramento e regulamentação. $\mathrm{O}$ aspecto fundamental na obtenção dos ganhos de eficiência é a adequada alocação de riscos entre os setores público e privado.

Por outro lado, contratos de PPP envolvem custos elevados em sua 
estruturação, licitação e posterior monitoramento, que devem ser considerados na avaliação do projeto. Analisando não só os custos de implementação do investimento, mas também os custos de transação resultantes, a opção pela contratação por meio de PPP, em oposição à contratação convencional de obra e serviços públicos, deve ser feita quando resultar em ganhos de eficiência e melhor relação custo-benefício?.

A evidência empírica dos ganhos de eficiência em contratos de parceria concentra-se sobretudo no Reino Unido dados o volume de projetos realizados e a diversidade de setores em que a PPP vem sendo empregada ${ }^{10}$. Estudo encomendado pelo Tesouro britânico aponta economias da ordem de 17\% nos contratos de PPP, quando comparados à alternativa de obra pública convencional (ENTERPRISE LSE, 2000). O documento destaca que os ganhos advêm principalmente da transferência de risco ao parceiro privado, da existência de competição no processo licita tório, dos incentivos gerados por mecanismos de pagamento associados a desempenho e da natureza contratual de longo prazo, que permite a otimização de custos ao longo do ciclo de vida do empreendimento. Outro trabalho (Construction Industry Council, 2002) aponta redução de custos de cerca de 10\% nos projetos de PPP, sendo que as maiores economias foram obtidas em projetos com um componente significativo de obras de engenharia, mas por meio de contratos que incluíam a prestação do serviço final. Além disso, maior eficiência foi observada nos casos em que a autoridade contratante era um órgão público central com um programa de projetos semelhantes ${ }^{11}$.

Análises conduzidas pelo National Audit Office (órgão central de controle, que corresponde ao Tribunal de Contas da União) e pelo Tesouro britânico chegaram a resultados expressivos no que se refere à eficiência da gestão privada dos projetos de PPP, quando comparadas à gestão de obra pública. De acordo com esses estudos, de $75 \%$ a $88 \%$ dos projetos de PPP foram concluídos dentro do prazo e orçamento previstos, contra apenas 30\% dos projetos realizados como obra pública convencional (Hм Treasury, 2003. National Audit Office, 2003).

\section{Características dos contratos de PPP}

A parceria público-privada é um modelo de contratação de serviços públicos em que a remuneração do particular é feita, parcial ou integralmente, pelo Estado. É uma mudança da lógica de aquisição de ativos para uma de compra de serviços, o que acarreta alteração fundamental na estrutura de incentivos do contrato. Sendo responsável pelo projeto, construção, financiamento e operação dos ativos necessários à disponibilização do serviço, o particular é incentivado a adotar uma visão integrada do ciclo de vida do empreendimento, o que estimula, além de eficiência, melhor qualidade na prestação do serviço.

A estruturação de um projeto de parceria segue normalmente o formato de um Project Finance, que é uma forma de financiamento de um investimento de capital economicamente separável, que tem no fluxo de caixa do projeto a fonte de pagamento dos empréstimos e do retorno do capital investido (Finnerty, 1996). Para o desenvolvimento do empreendimento, os investidores e patrocinadores constituem uma sociedade de propósito específico (SPE), cujos ativos e obrigações estão fora do balanço dos acionistas, limitando sua responsabilidade aos capitais aportados no projeto ${ }^{12}$.

A alocação de riscos em um Project Finance é feita por meio de uma complexa 
estrutura contratual, que, para o caso de uma concessão ${ }^{13}$ de serviço público, pode envolver: autoridade contratante, investidores, bancos, seguradoras, fornecedores de insumos, empresa construtora, operador e, quando é o caso, comprador da produção ${ }^{14}$ (Figura 1).

Essa intrincada teia de contratos segmenta e compartilha o risco entre as diversas partes, possibilitando que cada agente fique responsável pela parcela de risco que mais lhe convém e que pode melhor gerenciar.

Uma das questões mais importantes nos projetos de parceria é a alocação dos riscos entre as partes. Conforme se discutirá na seção seguinte, a lei brasileira de PPP inova ao permitir que o poder público transfira para o particular riscos que tradicionalmente são de responsabilidade da administração pública. A alocação de riscos nos projetos de PPP será feita contratualmente, dependendo do setor e do escopo do serviço. No entanto, pela experiência internacional, tipicamente o parceiro privado assume os riscos associados a projeto, construção do empreendimento (principalmente no que se refere a custos e prazos), manutenção, operação e prestação do serviço, riscos financeiros (cambial e de taxa de juros) e

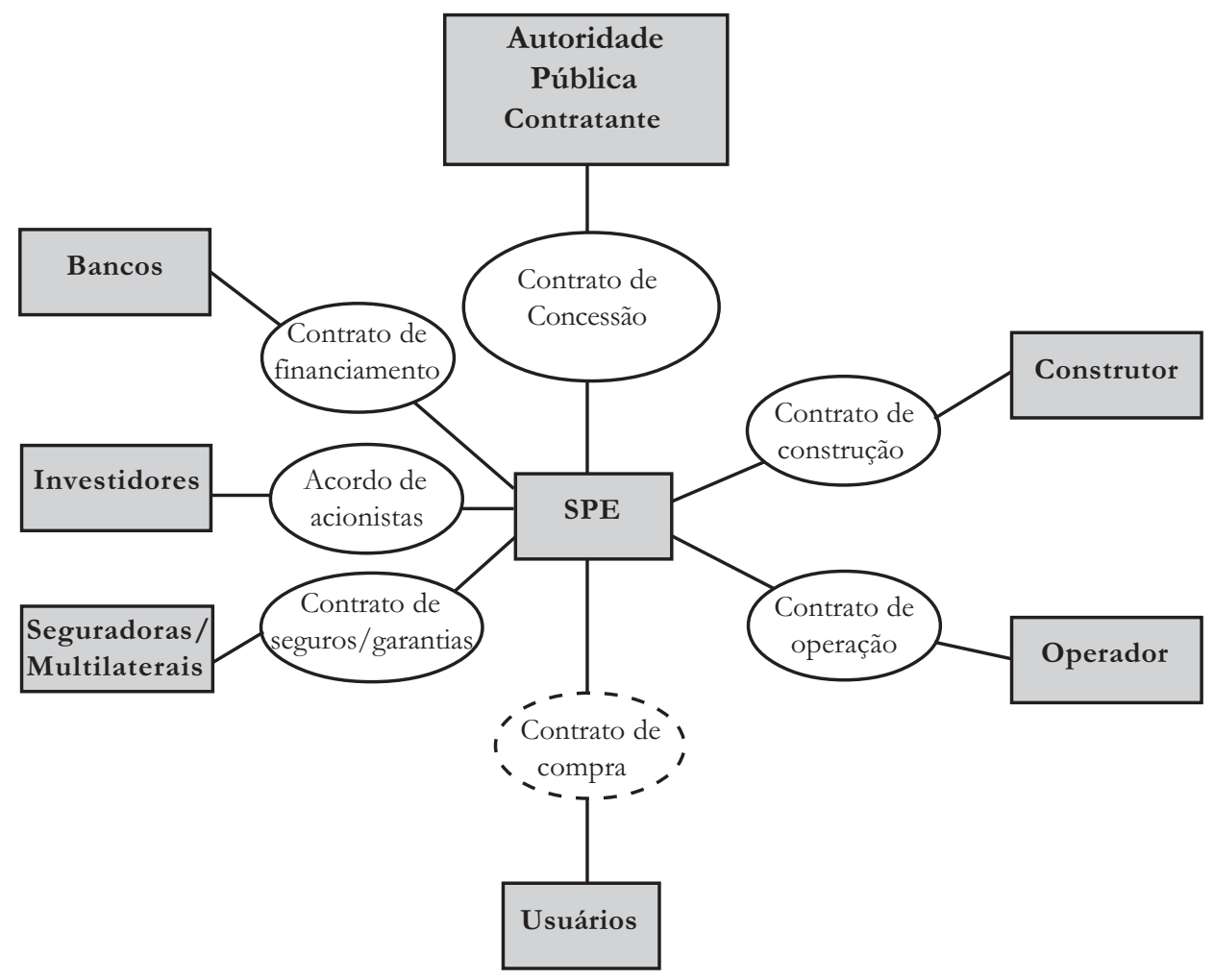

Figura 1: Relação contratual entre os diversos agentes envolvidos em uma concessão de serviço público (adaptado de Merna; SMITH, 1994). 
demais riscos comerciais. $\mathrm{O}$ poder público fica com os riscos de planejamento, desapropriação ${ }^{15}$, licenciamento ambiental prévio $^{16}$, mudança geral de legislação, podendo compartilhar com o parceiro privado riscos de força maior e caso fortuito. Já existem, no entanto, em diversos países, projetos em que o ente privado assume, integral ou parcialmente, tais riscos.

Um dos riscos chave em um projeto de PPP, que é objeto de rigorosa análise dos financiadores, é o risco de demanda. Ao contrário dos contratos de concessão comum, em que o risco de demanda é claramente do concessionário, nos contratos de PPP ele é normalmente compartilhado. Isso significa que, para tornar o empreendimento viável, o ente público mitiga o risco de demanda, seja por meio de uma complementação de receita fixa, seja por meio de remuneração variável. Em qualquer caso, o mecanismo de pagamento é condicionado à disponibilização do serviço e pode variar segundo padrões de desempenho.

A duração do contrato deve ser estabelecida com base no tipo de ativo e na natureza do serviço, de modo que o investimento inicial feito pelo particular seja recuperado em um prazo adequado. $\mathrm{O}$ contrato deve ser suficientemente longo para que o setor privado tenha o incentivo de investir em material, equipamentos e tecnologia, além de adotar uma gestão de serviços que otimize os custos ao longo da vida útil do projeto. Por outro lado, contratos muito longos podem ser bastante inflexíveis, caso não sejam previstos mecanismos de revisão periódica.

Tendo sido analisadas algumas características dos contratos de PPP, cabe agora explicitar o modelo brasileiro de parcerias e verificar de que forma a Lei n ${ }^{0} 11.079 /$ 2004 disciplina a matéria. Serão discutidos, na próxima seção, os aspectos centrais da lei, com destaque para alguns pontos que foram objeto de intenso debate durante o processo de aprovação legislativa.

\section{O modelo brasileiro de PPP:} Lei $\mathrm{n}^{\circ} 11.079 / 2004$

A Lei $n^{\circ} 11.079 / 2004$, aprovada em 30 de dezembro de 2004, institui as normas gerais para licitação e contratação de parceria público-privada no âmbito da administração pública ${ }^{17}$.
"A lei define ainda 'a repartição de riscos entre as partes, inclusive os referentes a caso fortuito, força maior, fato do príncipe e álea econômica extraordinária', o que representa alteração significativa do regime tradicional de repartição de riscos entre a administração e os entes privados"

A lei define parceria público-privada como um contrato de prestação de serviços, sendo vedada a celebração de contratos que tenham por objetivo único o fornecimento de mão-de-obra, equipamentos ou execução de obra pública ${ }^{18}$. Estabelece ainda um valor mínimo de contrato de $\mathrm{R}$ \$ 20 milhões. A fixação desselimite teve como objetivo afastar a possibilidade de que serviços de baixo valor contratual, 
contratados normalmente pela Lei $\mathrm{n}^{\circ}$ 8.666/1993, viessem a ser licitados como PPP. Como explicitado anteriormente, contratos de PPP têm uma estrutura contratual complexa e envolvem elevados custos de transação. Não são, portanto, adequados a projetos e serviços de pequena escala, em que um potencial ganho de eficiência não comportaria os custos de transação associados.

Para não deixar dúvidas quanto ao regime aplicável às PPP e, sobretudo, para diferenciá-las das concessões comuns regidas pela Lei $n^{\circ} 8.987 / 1995$, a lei adota uma estrutura conceitual que define como parceria público-privada o "contrato administrativo de concessão, na modalidade patrocinada ou administrativa", em que:

- concessão patrocinada é a concessão de serviços ou obras públicas de que trata a Lei $n^{\circ} 8.987 / 1995$ quando envolver, adicionalmente à tarifa cobrada dos usuários, complementação de receita pela autoridade pública em forma de contraprestação pecuniária; ${ }^{19}$

- concessão administrativa é o contrato de prestação de serviços de que a administração pública seja usuária direta ou indireta, cabendo a ela o pagamento integ ral ao parceiro privado.

A vantagem dessa terminologia é a possibilidade de remeter alguns aspectos da lei de PPP à legislação existente de concessão e licitação. Dessa forma, para a concessão patrocinada, por se tratar de prestação de serviço público ao usuário, aplica-se subsidiariamente o disposto na lei de concessões. Esse é o caso, por exemplo, da concessão de uma rodovia em que a cobrança de tarifa módica não seria suficiente para recuperar o investimento e remunerar o capital, sendo necessária uma complementação de receita pela autoridade pública para tornar o empreendimento viável.
Já para as concessões administrativas, em que o usuário da prestação de serviço é a própria administração pública, ainda que de maneira indireta, o regime predominante é o da lei de PPP, aplicando-se adicionalmente alguns dispositivos da lei de concessões. Seria o caso, por exemplo, de contratos para construção, manutenção e gestão de hospitais e escolas públicas, em que, embora exista um beneficiário (o cidadão), é a própria administração a usuária indireta do sistema, por ser ela a compradora do serviço prestado pelo parceiro privado. A administração adquire o serviço com o objetivo de disponibilizá-lo gratuitamente ao cidadão. Não há, portanto, cobrança de tarifa do beneficiário.

A lei define o prazo mínimo de cinco e máximo de 35 anos para os contratos de parceria, já incluindo eventual prorrogação. Define ainda "a repartição de riscos entre as partes, inclusive os referentes a caso fortuito, força maior, fato do príncipe e álea econômica extraordinária”. Esse dispositivo representa uma alteração significativa do regime tradicional de repartição de riscos entre a administração e os entes privados. Nos contratos administrativos em geral, regidos pela Lei no 8.666/ 1993, o poder público arca com o ônus integral desses riscos, cabendo ao ente privado assumir apenas os riscos referentes à álea econômica ordinária. A lei de PPP permite, portanto, que a alocação de riscos seja feita contratualmente, o que é uma importante inovação no direito administrativo brasileiro.

Os particulares têm tradicionalmente recorrido à garantia constitucional ao equilíbrio econômico financeiro nos contratos administrativos para impedir a efetiva transferência de riscos para a iniciativa privada. A Constituição Federal, no entanto, deixa claro que os termos do equilíbrio econômico-financeiro são defi- 
nidos em lei. Será possível, portanto, pela Lei $\mathrm{n}^{\circ} 11.079 / 2004$, alterar o regime convencional de repartição de riscos entre a administração pública e os entes privados nos contratos de parceria.

Outra importante inovação trazida pela lei de PPP é a possibilidade de prever, no contrato, os chamados step-in-rights. Tratase do direito do financiador de intervir no controle da sociedade de propósito específico, em caso de inadimplência dos contratos de financiamento ou de queda nos níveis de retorno a patamares que comprometam o cumprimento das obrigações futuras. O contrato definirá “'os requisitos e condições em que o parceiro público autorizará a transferência do controle da sociedade de propósito específico para os seus financiadores, com o objetivo de promover a sua reestruturação financeira e assegurar a continuidade da prestação dos serviços". 'Tal dispositivo não altera a prerrogativa da administração de intervir na concessionária para garantir a segurança e a continuidade da prestação dos serviços.

A lei de PPP institui um mecanismo fundamental de incentivo à eficiência na gestão dos contratos de parceria: a obrigatoriedade de vinculação do pagamento da contraprestação pública à disponibilização do serviço. A lei prevê ainda a possibilidade de se estabelecer contratualmente remuneração variável de acordo com metas e padrões de desempenho.

De modo a mitigar o risco de não cumprimento das obrigações pecuniárias contraídas pela administração pública nos contratos de PPP, são permitidas vinculação de receitas, instituição de fundos especiais, contratação de seguro-garantia com companhias seguradoras e garantias com organismos multilaterais, além daquela prestada por fundo garantidor ou empresa estatal criada para essa finalidade. $\mathrm{Na}$ esfera federal, a lei autoriza a União, suas autarquias e fundações públicas a participar, no limite de R\$ 6 bilhões, do Fundo Garantidor das Parcerias Público-Privadas (FGP).

O FGP terá natureza privada e patrimônio próprio separado do patrimônio dos cotistas, o que afasta a possibilidade de contingenciamento e execução em regime de precatórios. A integralização de suas cotas poderá ser feita em dinheiro, títulos da dívida pública, bens imóveis dominicais, bens móveis, inclusive ações de sociedade de economia mista federal excedentes ao montante necessário à manutenção de seu controle pela União. A criação, administração e gestão do FGP serão feitas por instituição financeira controlada, direta ou indiretamente, pela União.

Uma das questões mais debatidas durante o processo legislativo foi a forma de contabilização das obrigações contraídas pelo poder público nos contratos de PPP, se como despesa corrente ou de capital. No momento ainda não foi desenvolvido um padrão internacionalmente aceito de contabilização de operações de PPP e a prática varia enormemente entre os países (Fundo Monetário INTERNACIONAL, 2004). Há, no entanto, algumas diretrizes que orientam uma forma de contabilização cujo critério determinante é o do interesse econômico no ativo, o que está diretamente relacionado ao grau de transferência de risco ao parceiro privado. Em fevereiro de 2004, o órgão de estatística da União Européia - Statistical Office of the European Communities (Eurostat) - publicou uma decisão sobre o tratamento contábil das $\mathrm{PPP}^{20}$. O Eurostat recomenda que o ativo objeto do contrato não seja contabilizado no balanço patrimonial público se duas condições forem atendidas: a) o parceiro privado assume o risco de construção do 
empreendimento; e b) o parceiro privado assume pelo menos um dos seguintes riscos: disponibilidade ${ }^{21}$ ou demanda. Assim, nos casos em que o privado arca com parcela significativa do risco, considera-se que é ele quem tem interesse econômico no ativo, e a compra do serviço pelo poder público é contabilizada como despesa corrente. Contrariamente, se o risco de construção é do governo, ou o particular assume apenas o risco de construção e nenhum outro, os ativos devem constar do balanço patrimonial público e ser contabilizados como dívida. No caso brasileiro, a lei de PPP atribui à Secretaria do Tesouro Nacional a competência para editar as "normais gerais relativas à consolidação das contas públicas aplicáveis aos contratos de parceria público-privada”.

Com o objetivo de evitar que as obrigações com os pagamentos da contraprestação pública representassem risco de indisciplina fiscal e viessem a comprometer parcela substancial do orçamento público, a lei estabeleceu ainda um limite de $1 \%$ da receita corrente líquida ${ }^{22}$ para a soma das despesas anuais derivadas do conjunto dos contratos de parceria celebrados pela União. A concessão de garantias e transferências voluntárias da União para os estados, Distrito Federal e municípios estará condicionada ao cumprimento, pelos entes subnacionais, do limite de $1 \%$ da receita corrente líquida com suas obrigações anuais de contratos de PPP.

Um dos pontos mais destacados na experiência internacional como fundamental para a boa condução de programas de parceria público-privada é a existência de um órgão público central, responsável por coordenar a implementação dos projetos, desenvolver expertise em PPP e disseminá-la pelos órgãos da administração pública. A Lei no 11.079/2004 define as competências do órgão gestor de parcerias público-privadas, a ser instituído por decreto. Composto por representantes do Ministério do Planejamento, Orçamento e Gestão (MP), do Ministério da Fazenda (MF) e da Casa Civil da Presidência da República, sob a coordenação do MP, o órgão gestor tem a competência de definir os serviços a serem contratados por meio de parcerias, disciplinar os procedimentos para a celebração dos contratos, autorizar abertura de licitação, a provar seu edital e apreciar os relatórios de execução dos contratos. Participará das reuniões do órgão gestor um representante do ministério setorial cuja área de competência seja relacionada ao projeto em análise. A deliberação do órgão gestor sobre um projeto de parceria público-privada deverá estar baseada em pronunciamento do Ministério do Planejamento sobre o mérito do projeto e do Ministério da Fazenda sobre a viabilidade e forma de concessão de garantias, relativamente aos riscos fiscais e ao cumprimento do limite de despesa com contratos de PPP.

Concluída a regulamentação da Lei n ${ }^{\circ}$ 11.079/2004, o governo federal dará início à implementação do programa de parcerias. Com foco na área de infraestrutura, dado seu papel fundamental na sustentabilidade do desenvolvimento econômico, os primeiros projetos de PPP no âmbito federal estão sendo selecionados de modo a estruturar sistemas logísticos, com uma visão integrada de planejamento e objetivando eliminar gargalos nos principais corredores de exportação ${ }^{23}$. A PPP representará, assim, um importante instrumento para viabilizar um programa de investimentos urgentes e necessários ao país.

\section{Conclusão}

A adoção de programas de PPP em diversos países do mundo vem sendo impulsionada, por um lado, pela necessidade de dar continuidade ao investimento 
estatal em um contexto de restrição fiscal e, por outro, pela busca de maior eficiência na prestação dos serviços públicos.

A experiência internacional demonstra que, quando bem implementados, programas de parceria podem representar uma alternativa interessante para viabilizar empreendimentos de maneira eficiente e eficaz.

$\mathrm{Na}$ elaboração da lei brasileira, foram incorporados elementos considerados em outros países como fatores críticos de sucesso. Dentre eles, destacam-se o enquadramento ao sistema legal existente, a preocupação com a disciplina fiscal, a adequada repartição de riscos entre os parceiros, as garantias ao parceiro privado e a necessidade de se instituir um órgão central para coordenar o processo de implementação das parcerias.

Ainda que a lei discipline as questões mais importantes relativas aos projetos de PPP, serão definidos, em cada contrato, a alocação de riscos, os mecanismos de incentivo, as metas e os padrões de desempenho. A aprovação da lei representou, assim, o primeiro passo de um processo de consolidação das parcerias públicoprivadas como mais um instrumento para viabilizar os investimentos de que o país tanto necessita.

(Artigo recebido em março de 2005. Versão definitva em março de 2005)

\section{Notas}

${ }^{1} \mathrm{O}$ presente artigo expressa exclusivamente a opinião dos autores, não representando qualquer manifestação ou posição do Governo Federal.

${ }^{2}$ A experiência do sistema produtivo estatal francês ilustra esse tipo de resposta.

${ }^{3}$ Os EUA foram a notável exceção, uma vez que a melhoria do seu quadro fiscal na segunda metade dos anos 90 decorreu primordialmente da espetacular performance em termos de crescimento econômico - o tão citado pacote fiscal do primeiro governo Clinton não passou de um tímido ajuste marginal, quando comparado, guardadas as devidas proporções, aos ajustamentos europeus e latinoamericanos (ver BLINDER; YeLLEN, 2001). Mesmo assim, desde 2001 observou-se uma deterioração do déficit público americano, fruto de uma combinação de ativismo fiscal e recessão.

${ }^{4}$ Os critérios de convergência estabelecidos no Tratado de Maastricht tinham por objetivo disciplinar a política fiscal dos países da Zona Euro para a introdução da moeda única. Entre outras medidas, impunha um teto de $3 \%$ do PIB ao déficit público.

${ }^{5} \mathrm{O}$ conceito de PPP adotado no Reino Unido abrange desde o PFI até as concessões, terceirizações e privatizações (Hм'TreAsury, 2000).

${ }^{6}$ O pedágio-sombra (tradução livre do termo inglês shadow-toll) é um mecanismo de pagamento em que o poder público remunera integralmente o concessionário com base no tráfego real. Concebido nos primeiros contratos de rodovias no Reino Unido, foi adotado em Portugal no programa de concessões SCUT (Sem Cobrança ao Utilizador). O governo português estima, para 2005, um compromisso de pagamento com tais contratos da ordem de 500 milhões de euros, o que representa a totalidade do orçamento do Instituto das Estradas de Portugal (IEP). Está em curso um processo de renegociação desses contratos para que se institua a cobrança de pedágio real (CARDOSO, 2004). 
${ }^{7}$ Para uma discussão sobre tais argumentos, ver Stiglitz (2000) e Mumford (1998).

${ }^{8}$ A eficiência produtiva baseia-se na minimização de custos para uma dada produção ou no ganho de produtividade resultante de processos inovadores. Já a eficiência alocativa volta-se para a obtenção de produtos que a sociedade considera socialmente aceitáveis e cujos benefícios igualam ou superam o custo marginal de produzi-los (MARTIN; PARKER, 1999).

${ }^{9}$ Para uma discussão sobre a economia dos custos de transação no contexto da PPP, ver Mumford (1998).

${ }^{10}$ Desde o início dos anos 90, mais de 600 contatos de PPP/PFI foram assinados no Reino Unido, com um valor total de mais de 60 bilhões de euros. Os setores com maior volume de investimentos de PPP são os de transportes, saúde, educação e defesa. (Fonte: PFI Statistics. Disponível em www.hm-treasury.gov.uk).

${ }^{11}$ Esse é o caso das estradas e prisões inglesas, em que a autoridade contratante é uma agência central (Highways Ag ency e HM Prison Service), que lançaram programas de PPP, e não projetos isolados. No caso dos hospitais ingleses, a licitação dos projetos é feita de modo descentralizado.

${ }^{12}$ A Lei de PPP estabelece a obrigatoriedade de constituição de uma SPE para a implantação e gestão do objeto da parceria.

${ }^{13} \mathrm{O}$ termo concessão aqui empregado abarca tanto as concessões comuns quanto as PPP. Como será visto posteriormente, a lei brasileira define parceria público-privada como um contrato administrativo de concessão.

${ }^{14}$ É o caso dos contratos de concessão para geração de energia, em que há possibilidade de estruturar o projeto com base em contratos de compra e venda (take-or-pay), reduzindo, portanto, o risco de demanda.É diferente, por exemplo, de uma concessão de rodovia pedagiada em que a receita do concessionário advém de tarifas cobradas dos usuários.

${ }^{15}$ Já existem casos em alguns países, inclusive no Brasil, em que a desapropriação fica a cargo do particular, tendo por base um valor estabelecido previamente no edital.

${ }^{16}$ A Lei de PPP permite que a licitação esteja condicionada à expedição de diretrizes para o licenciamento ambiental, cabendo ao parceiro privado a obtenção de licença ambiental prévia.

${ }^{17}$ A lei se aplica aos Poderes da União, dos estados, do Distrito Federal e dos municípios. Alguns estados já aprovaram leis de PPP. Como compete à União legislar em matéria de licitações e contratos, as leis subnacionais devem estar submetidas à lei 11.079/2004. Em caso de conflito, prevalece a legislação federal.

${ }^{18}$ Quando o contrato envolver execução de obra, esta deve ser necessária à prestação do serviço.

${ }^{19}$ A lei define um limite para a contraprestação pública de $70 \%$ da remuneração do parceiro privado. As concessões patrocinadas em que a contrapr estação exceder esse limite requerem autorização legislativa específica.

${ }^{20}$ É interessante notar que a diretriz do Eurostat se aplica a projetos de PPP em que o setor público é o principal comprador do serviço disponibilizado pelo concessionário. No modelo brasileiro, esse seria o caso das concessões administrativas. Poderia também ser entendida como aplicável às concessões patrocinadas em que a contrapartida pública representasse a maior parte da remuneração do parceiro privado. No entanto, para as concessões patrocinadas em que o componente de receita proveniente da contraprestação pública é pequeno em relação à parcela de tarifa cobrada do usuário, pode-se entender que a forma de contabilização se guiria o modelo das concessões comuns.

${ }^{21}$ Considera-se que há transferência de risco de disponibilidade quando o pagamento ao parceiro privado está condicionado à disponibilização do serviço, de acordo com padrões de desempenho previamente especificados. Atraso no prazo de construção ou interrupção do serviço por razões 
outras que não aquelas explicitamente consideradas extraordinárias pelo contrato acarretam na suspensão da contraprestação pública. Além disso, o não-cumprimento dos padrões de desempenho estabelecidos contratualmente implica deduções do pagamento. A lei de PPP define daramente que "a contraprestação da Administração Pública será obrigatoriamente precedida da disponibilização do serviço objeto do contrato".

22 A Lei Complementar n¹01/2000 define receita corrente líquida como o somatório das receitas tributárias, de contribuições, patrimoniais, industriais, ag ropecuárias, de serviços, transferências correntes e outras receitas também correntes, deduzidos, no caso da União, os valores transferidos aos estados e municípios por determinação constitucional ou legal e as contribuições trabalhistas e de seguridade social. No ano de 2004 a receita corrente líquida da União foi de cerca de R $\$ 260$ bilhões.

${ }^{23}$ Nessa primeira etapa, serão privilegiados projetos que tenham alguma capacidade de geração de receitas, ou seja, contratos de concessão patrocinada.

\section{Referências bibliográficas}

Blinder, A. S.; Yellen, J. L. The Fabulous Decade: macroeconomic lessons from the 1990s. Nova York: Century Foundation Press, 2001.

CArdoso, F. IEP colapsa com SCUTS. O Independente. Lisboa, p. 3, 10 set. 2004.

Construction Industry Council. The Role of Cost Saving and Innovation in PFI Projects. Londres: Thomas Telford, 2002.

Enterprise Lse. Value for Money Drivers in the PFI - a report by Arthur Andersen and Enterprise LsE, Commissioned by The Treasury Taskforce. Londres, 2000.

Eurostat. Eurostat News Release 18/2004: treatment of public-private partnerships. 11 fev. 2004.

Finnerty, J. D. Project Financing: Asset-based Financial Engineering. Nova Jer sey: Wiley, 1996.

Fundo Monetário Internacional. Public Investment and Fiscal Policy. Washington, 2004. HM Treasury. Public Private Partnerships: the government's approach. Londres: HMSO, 2000. . PFI: meeting the investment challenge. Londres: HMSO, 2003.

Merna, T.; Smith, N. J. Projects procured by privately financed concession contracts. Manchester: UMIST, 1994.

Mumford, M. Public projects, private finance: understanding the principles of the private finance initiative. Welwyn Garden City: Griffin Multimedia, 1998.

National Audit Office. PFI: construction performance. Londres: HMSO, 2003.

Stiglitz, J. E. Economics of the Public Sector, 3a ed. Nova York: W. W. Norton \& Co, 2000. 


\section{Resumo - Resumen - Abstract}

\section{Parceria público-privada: compreendendo o modelo brasileiro Barbara Moreira Barbosa de Brito e Antonio Henrique Pinheiro Silveira}

A necessidade de viabilizar investimentos públicos em um contexto de restrição fiscal impulsionou governos de diversos países a buscar na parceria com o setor privado a alternativa para a realização de obras e serviços públicos. A experiência paradigmática do Reino Unido em programas de parceria público-privada (PPP) norteou a implantação de iniciativas semelhantes mundo afora. No Brasil, a aprovação, em dezembro de 2004, da lei que disciplina as normas para contratação de PPP deu início a um processo que passará pela definição dos projetos prioritários e que culminará na consolidação das parcerias como mais um instrumento para a viabilização de obras e serviços públicos de que o país necessita. Esse artigo tem por objetivo elucidar o modelo brasileiro de parcerias público-privadas. Após uma contextualização inicial, são discutidos os fundamentos que balizam a implantação de um programa de PPP e apresentadas algumas características gerais dos contratos. Por fim, são expostos os pontos centrais da lei brasileira.

Palavras-chave: parceria público-privada (PPP); infra-estrutura; concessão

\section{Asociación público-privada: comprensión del modelo brasileño \\ Barbara Moreira Barbosa de Brito y Antonio Henrique Pinheiro Silveira}

El desafío de realizar inversiones publicas en una situación donde los Estados no cuentan con los recursos necesarios llevó a los gobiernos a convocar al sector privado a participar en los procesos de inversión, manutención y explotación de obras y servicios públicos. El modelo británico fue una referencia a muchos países que adoptaran un programa de asociación público-privada. En Brasil, la aprobación del marco legal en Diciembre de 2004 representa el principio de un proceso que implicará en la selección de proyectos prioritarios y en la aplicación de la ley a las inversiones que el país necesita. Este artículo examina las bases del prog rama brasileño. Describe los antecedentes relacionados con los programas de asociación, presenta algunas características generales de los contratos y al fin discute la ley federal brasileña en asociaciones público-privadas.

Palabras clave: asociación público-privada; infraestructura; concesión

\section{Public-private partnership: understanding the Brazilian framework Barbara Moreira Barbosa de Brito and Antonio Henrique Pinheiro Silveira}

The need to provide public infrastructure under budgetary constraints fostered many governments to seek partnership with the private sector. The experience of the United Kingdom in procuring public services under a public-private partnership (PPP) framework became a paradigm to many governments seeking to implement a PPP program. In Brazil, the approval in December 2004 of the new PPP Law was the starting point of a process that will involve selecting priority projects and applying the new legal instrument to contracting infrastructure projects and providing public services. This article examines the foundations of the Brazilian PPP program. It sets the context under which partnership programs are conceived, presents some general features of PPP contracts and finally discusses the Brazilian federal law on public-private partnerships.

Keywords: public-private partnership (PPP); infrastructure; concession 
Barbara Moreira Barbosa de Brito

Engenheira civil e mestre em Economia e Gerenciamento da Construção pela University College London. É Especialista em Políticas Públicas e Gestão Governamental e atua na Unidade PPP do Ministério do Planejamento. Contato: barbara.brito@planejamento.gov.br

Antonio Henrique Pinheiro Silveira

Doutor em Economia pelo IE/UFRJ, Chefe Adjunto da Assessoria Econômica e Coordenador da Unidade PPP do Ministério do Planejamento. É professor adjunto licenciado da Faculdade de Ciências Econômicas da UFBA. Contato: antonio.silveira@planejamento.gov.br. 


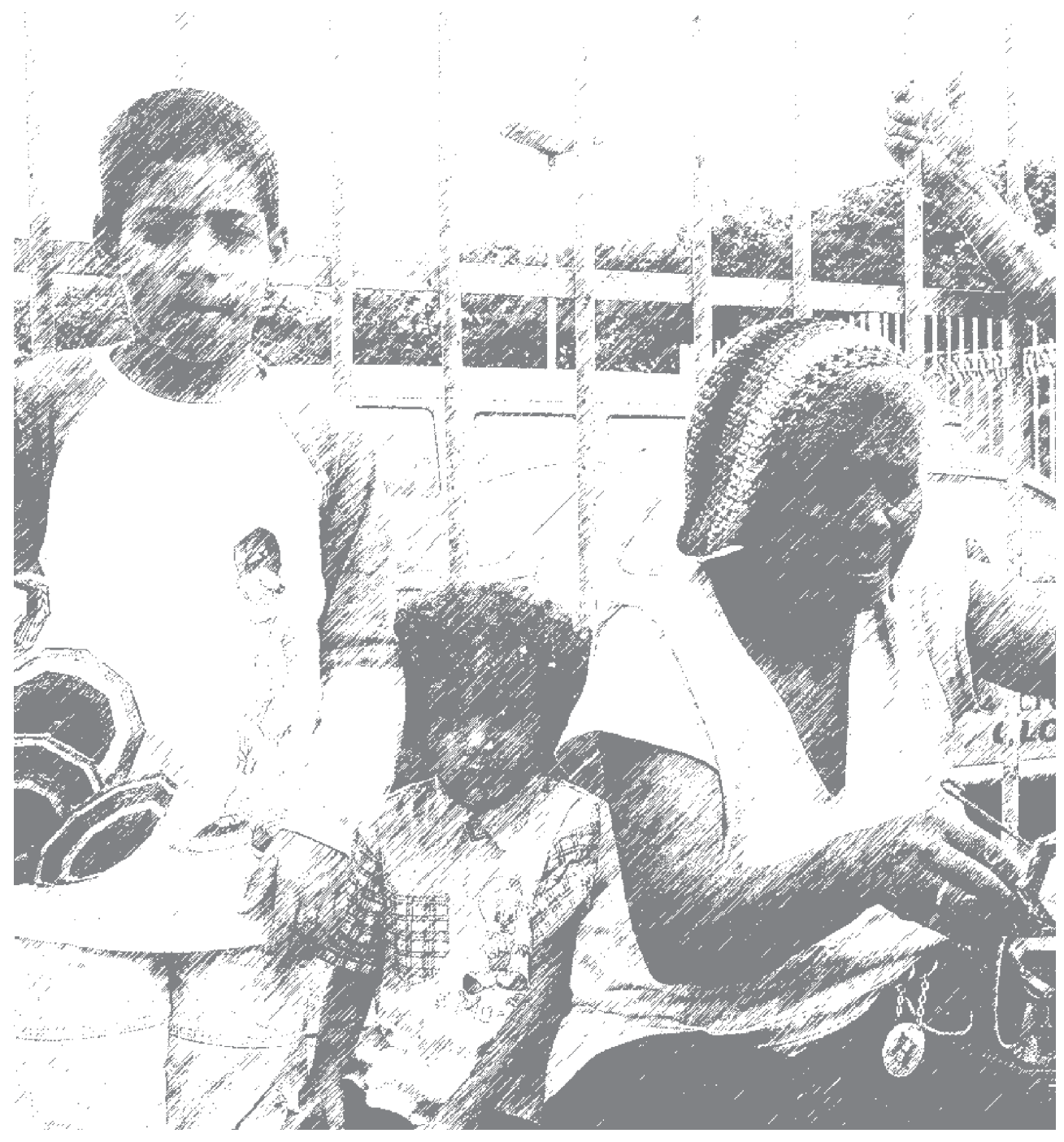

